\title{
ENTRE O CRÍTICO E O TIPÓGRAFO: MACHADO DE ASSIS E A INVENÇÃO DE ESPAÇOS EDITORIAIS, EM DOIS TEMPOS
}

\section{RACHEL BERTOL}

Universidade Federal Fluminense

Niterói, Rio de Janeiro, Brasil

\section{BRUNO GUIMARÃES MARTINS}

Universidade Federal de Minas Gerais

Belo Horizonte, Minas Gerais, Brasil

Resumo: $\mathrm{O}$ artigo aborda dois momentos do percurso de Machado de Assis na oficina de tipografia de Paula Brito (1809-1861) e a aclamação de sua obra na última década do século XIX. Nesse segundo momento, toma-se como ponto de partida sua relação com o crítico literário José Veríssimo (1857-1916). Trata-se de duas parcerias estratégicas, que podem esclarecer pontos de inflexão e posicionamentos do escritor no circuito editorial. Das lições de tipografia da juventude, tornando-se mestre dos jogos com as letras impressas, o escritor termina o século como protagonista das transformações no meio editorial do país, agregando escritores e inventando, a partir de sua obra, uma nova perspectiva crítica para a literatura brasileira.

Palavras-chave: Francisco de Paula Brito; José Veríssimo; crítica literária; tipografia.

\section{BETWEEN THE CRITIC AND THE TYPOGRAPHER: MACHADO DE ASSIS AND THE INVENTION OF EDITORIAL SPACES, IN TWO STAGES}

Abstract: The article discusses two stages of Machado de Assis's career in Paula Brito's typography workshop (1809-1861) and the acclaim of his work in the last decade of the nineteenth century. The second stage is based on his relationship with the literary critic José Veríssimo (1857-1916). These are two strategic partnerships, which can explain turning points for Machado and his positions in the editorial circuit. From his lessons on typography in his youth, which influenced his way of writing, he ends the century as a prominent figure in the editorial transformations in Brazil, thereby bringing together writers and inventing, based on his work, a new critical perspective for Brazilian literature.

Keywords: Francisco de Paula Brito; José Veríssimo; literary criticism; typography. 


\section{Parcerias estratégicas}

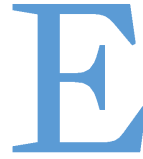

ste artigo tem como objetivo atar duas pontas da vida: trata-se de traçar dois retratos, em dois tempos, a respeito do início e do fim da trajetória de Machado de Assis no que se refere à sua atuação no circuito editorial. Se a juventude costuma ser um período formativo na trajetória dos indivíduos, pode-se considerar que o ingresso do escritor na tipografia do editor Francisco de Paula Brito (1809-1861), ainda adolescente, o fez perceber o funcionamento do circuito editorial "por dentro", contribuindo em sua formação para a construção de seu estilo de escrita literária. Assim, essa teria sido uma primeira associação estratégica.

$\mathrm{Na}$ outra ponta da vida, temos a figura do crítico José Veríssimo (1857-1916), que, como lembra Guimarães (2004), Machado o via como seu "leitor ideal". Se Veríssimo, desde a crítica a Quincas Borba, publicada em janeiro de 1892 no Jornal do Brasil, se tornou o crítico "mais desenvolvido" de Machado, segundo o próprio escritor, a relação entre eles teve repercussões práticas para a invenção de espaços editoriais: o crítico foi de certa forma um aglutinador do meio editorial, parceiro importante para a concretização de projetos, como o da Academia Brasileira de Letras (ABL) por meio de Revista Brasileira. Com Mário de Alencar e na sua História da literatura brasileira (1916), Veríssimo também desempenhou um papel importante para que se começasse a assegurar um lugar distinto para Machado, depois de sua morte, na literatura brasileira e, portanto, para que se tornasse uma presença constante e crescentemente valorizada no meio editorial.

As lições de tipografia dos primeiros anos contribuíram para que Machado se tornasse um mestre dos jogos criados com as letras impressas. Além disso, riso e humor eram elementos fartos na sociedade líterohumorística que se reunia ao redor de Paula Brito. Como podemos conferir nos registros de suas reuniões publicados nas colunas da Marmota Fluminense (1852-1859), a Petalógica era uma reunião informal que ocorria em frente à loja (tipografia) de Paula Brito. Importante notar que se reuniam ali diferentes personagens políticas, literárias e artísticas ao lado de anônimos, populares e curiosos cuja polifonia permitiu que a sociedade fosse chamada de "corpo sem cabeça" (MARTINS, 2018), sendo que a ausência de hierarquia favoreceu o ingresso de novos atores como Machado.

Essas "lições de humor" serviram para a vida e a obra. Curiosamente, o crítico "sem humor" - assim Wilson Martins define Veríssimo (apud BERTOL, 2016) - foi o primeiro a apontar a caraterística do humor em 
Machado, justamente na crítica a Quincas Borba. Desde então, as discussões "entre humor e humorismo estariam diretamente associadas à tensão entre o nacional e o universal na obra de Machado de Assis" (GUIMARÃES, 2004b, p. 279). Por sua vez, a reunião da correspondência de Machado (2011-2015) demonstra como sua relação com Veríssimo, interlocutor próximo e constante, comporta momentos jocosos, conectados a uma profunda crítica social. A cumplicidade intelectual com Veríssimo, sendo ambos ateus e mais próximos na idade, era ainda maior que com amigos importantes como Mário de Alencar e Magalhães de Azeredo (ROUANET, 2011, p. xi).

Machado, segundo Albuquerque, reconhecia a "existência de um mundo literário concreto, que tem uma geografia, uma construção, uma temporalidade, uma moral, leis e políticas próprias" (2017, p. 110). A consciência dessa concretude, inclusive pelo reconhecimento, destaca o autor, de que o Brasil teria um capital literário "pobre e que carece de corporização", explicaria a atuação lúcida de Machado no circuito editorial. O escritor foi tenaz na militância ao colaborar para jornais, agregar pessoas, inaugurar agremiações e propiciar, com seus escritos, a invenção de uma perspectiva crítica nova na literatura brasileira. Assim, não se pode compreender a atuação de Machado no circuito editorial de seu tempo sem levar em conta que ele era um agente ativo: ao inventar para si espaços de afirmação literária, ele também o transformava.

Se sua obra, a partir das lições de tipografia de Paula Brito, oferece-se em enigmas, o crítico, sendo um leitor especial, é aquele que mais perto chegaria de decifrá-la. Veríssimo, nesse aspecto, foi seu principal aliado. A seguir, apresentaremos breves retratos desses dois momentos para, por fim, retomar a teia de aspectos que nos permitiram reuni-los neste quadro.

\section{O escritor e o tipógrafo}

No primeiro momento, o jovem Machado encontra espaço para suas aspirações lançando mão de seus conhecimentos da língua, necessários a um aprendiz de tipógrafo, como se encontra registrado no Manual da tipografia brasiliense: "um aprendiz deve conhecer bem a sua língua" (OGIER, 1832, p. 56). Acolhido nas oficinas do "tipógrafo-editor" Paula Brito, o jovem continuou sua experiência na Tipografia Nacional entre 1856 e 1858, sob a direção de um já reconhecido Manuel Antônio de Almeida: "Em função do cargo de que estava investido, ele recebia quase que queixas diárias do chefe das oficinas sobre um rapaz aprendiz de tipógrafo 'cujo trabalho não rendia', 
pois largava constantemente a ocupação para ir ler nos cantos poucos frequentados da oficina" (SCHAPOCHNIK, 2008, p. 386). A despeito das distrações de leitura, junto a compositores, impressores e revisores, o futuro autor observava de perto as etapas que transfiguravam um manuscrito em impresso, permitindo que reelaborasse tal experiência em suas reflexões literárias: "[...] em algumas crônicas, Machado de Assis encena de forma metalinguística as transposições do fazer tipográfico no fazer literário" (SCHAPOCHNIK, 2008, p. 386).

Se é verdade que a leitura precede a escrita, nos parece relevante ajuntar à caudalosa fortuna crítica de Machado algumas volutas a mais a propósito de sua caracterização como leitor. Sabemos que Machado lia na oficina tipográfica, mas nos interessa pensar também que lia como tipógrafo. Tal sensibilidade não era exclusiva de quem vivenciara o chão da oficina, uma vez que, especialmente na segunda metade do século XIX, tornaram-se populares na imprensa a publicação de jogos literários como enigmas tipográficos, charadas, logogrifos e anagramas. Essas excêntricas e enigmáticas microformas literárias se apresentavam como verdadeiros quebra-cabeças tipográficos, impondo ao leitor a manipulação de elementos significantes para que fossem decifrados, ou seja, demandavam percepção visual da palavra e da composição que deveriam ter letras e sílabas manipuladas, como se o leitor fosse um tipógrafo.

No conjunto de textos publicado sob o título Machado de Assis desconhecido, Raimundo Magalhães Júnior (1955) aponta para um procedimento criativo baseado em repetições, algo facilmente associado à atividade tipográfica. Se as recorrentes citações poderiam ser escolhidas aleatoriamente, era relevante que se encaixassem perfeitamente na grade textual, assim como um pequeno bloco tipográfico previamente composto que encaixasse novas composições:

[...] há citações favoritas, muitas delas, ou melhor, a maioria, colhidas em obras teatrais, que constituem uma espécie de ritornelo na prosa machadiana. Ele as usava indistintamente nas crônicas, nos contos e nos romances. A questão era calhar. Por vezes, a citação não corresponde exatamente ao texto citado. Citava de cor, sem recorrer aos livros, e a memória o traía, mesmo quando era Camões o citado. (MAGALHÃES JÚNIOR, 1955, p. 208, grifos nossos)

Do gesto repetitivo de citar decorre uma segunda constatação. O desvio consciente desculpado pelo autor como falhas da memória faria com 
que o mesmo crítico cunhasse uma expressão certeira para caracterizar o autor: "o deturpador de citações".

A 20 de janeiro de 1895, Machado reaproveitaria a reflexão de Hamlet para tirar dela, numa paródia feliz, um efeito diverso, de natureza satírica. É quando fala do jogo que se alastra na Capital Federal, como passara a chamar-se a antiga Corte: “...os bookmakers, apesar do nome, nunca escreveram livros, e que há entre uma casa e outra mais frontões do que sonha a minha vã filologia”. (MAGALHÃES JÚNIOR, 1955, p. 209)

Identificadas pela intuição erudita de Magalhães Júnior, as dinâmicas de repetição e deturpação espelham a dinâmica de trabalho em uma oficina tipográfica. Em termos similares - mas não idênticos - esta dinâmica demonstra força para a crítica contemporânea, como se pode verificar na formulação "poética da emulação" realizada por Rocha (2013). Ao modo do aprendizado da tradicional arte tipográfica, era necessário repetir um modelo para então abrir como possibilidade a diferença: "A técnica da emulação supõe partir da imitação consciente de um modelo prévio, com o objetivo de acrescentar-lhe dados novos" (ROCHA, 2013, p. 107). Dito disso, passemos a descrever com mais detalhe o que chamamos "leitor-tipógrafo", que se configurou pela leitura das charadas e jogos tipográficos publicados por um “tipógrafo-editor", expressão pela qual muitas vezes Paula Brito era chamado devido à explícita defesa da arte tipográfica.

Paula Brito apresenta uma série de semelhanças biográficas - mulato, literato, polímata, pioneiro - que certamente renderam a empatia necessária para que empregasse o jovem aspirante a escritor, conhecido como Machadinho nas rodas da Petalógica, "sociedade lítero-humorista". Afora o ceticismo que transbordava de quem defendia a disseminação da mentira ("peta") como engenhosa estratégia de "contrariar os mentirosos, mentindolhes", os petalógicos eram reconhecidos como mestres na solução e na elaboração de jogos tipográficos, ou seja, espécimes exemplares de "leitorestipógrafos", como podemos verificar nas orientações que acompanhavam uma charada elaborada por um leitor: "Excetuo deste concurso todos os membros efetivos, honorários, correspondentes e egressos da famosa Academia Petalógica, por serem os mais abalizados decifradores de charadas, logogrifos e adivinhações da terra". ${ }^{1}$

Em praticamente todos os números da Marmota Fluminense, folha de

${ }^{1}$ Correio Mercantil, n. 92, 27 mar. 1858. 
variedades publicada por Paula Brito, quando Machado trabalhou em suas oficinas, geralmente em sua quarta e última página, convocava-se o leitor para solucionar charadas, enigmas, logogrifos, adivinhação por letras ou para glosar motes a prêmio. Ao decifrar o jogo, o leitor recebia obras publicadas, assinaturas de periódicos, bilhetes de loterias entre outros impressos, além de ter sua resposta publicada com sua assinatura. Estimulavam-se respostas redigidas "com graça”, em geral na forma de versos. Esta fórmula de interação produtiva realizava, talvez, uma das mais ambiciosas expectativas de um editor: transformar leitores em autores.

O leitor-tipógrafo explorava e manipulava relações de valor na linguagem, modificando os significados pela inversão das expectativas iniciais. Por sua vez, tanto a redação poética a partir de motes quanto a leitura de charadas, enigmas e logogrifos solicitavam capacidades específicas. Para solucionar esses quebra-cabeças de letras, o leitor não dependia apenas de destreza interpretativa ou semântica, era necessário literalmente manipular letras e sílabas, invertê-las, substituí-las, decompô-las, combinálas. Era como se para ler fosse necessário ser tipógrafo. Nesse sentido, o leitor se aproximava ainda mais do operário das letras, se pensarmos que existiam prazos e compensações para ler e decifrar.

O leitor, que compunha e decompunha letras, sílabas e palavras, experimentava as potencialidades combinatórias da linguagem que se tornavam manipuláveis. Mesmo que não se dispensasse uma ordenação de significados, estimulavam-se percepções fonéticas e visuais. Leitores feitos tipógrafos transportavam-se para um universo metalinguístico, enquanto deslizavam por diferenças significantes na busca de soluções do enigma. Esse movimento pode ser facilmente visualizado comparando-se a longa extensão dos enigmas e sua curta solução, geralmente, uma palavra ou frase.

Sensibilizado pelo significante, além de deslocar-se para questões secundárias e superficiais, o leitor que ingressava no jogo das charadas espelhava práticas da produção de uma comunicação impressa. Ao convocar a demonstração de perspicácia e rapidez, estabelecia-se não só uma relação competitiva, mas um desafio temporal, que aproximava o leitor do tipógrafo, sempre apressado para finalizar a composição da edição. Ao elaborar charadas, o leitor-tipógrafo fornecia conteúdo para as colunas dos periódicos, vale dizer, com um custo muito baixo. Vejamos uma manifestação de profunda angústia do leitor diante da dificuldade de decifração de uma charada:

Faz hoje sete meses que vivo ocupado! Ocupadíssimo!... que insano trabalho. 
Meu Deus! penso, raciocino, conjecturo... quase que... Não tenho tempo para comer, beber e dormir; estou velho; magro e pálido; não saio de casa, não falo a ninguém!!! Até quando durará isto? Até que o redator da Marmota dê a decifração das duas charadas do n. 14, de 23 de outubro de 1849!!?

Em relação a jogos de leitura como aqueles propostos pelos logogrifos, a despeito de qualquer debate sobre sua qualidade literária, sua relevância consiste em compartilhar a experiência metalinguística do tipógrafo com o leitor, tornando-o sensível para o valor diferencial dos significantes. Ao repetir os gestos do tipógrafo, ou seja, ao compor, decompor e recompor letras, o leitor conscientizava-se do funcionamento modular da tipografia que caracterizava o impresso que tinha nas mãos. De certa forma, é o funcionamento da tipografia que se apresenta na leitura dos enigmas. Diante de movimentos de decomposição e recomposição, os jogadores agem sob o risco do "empastelamento", ou seja, desorganização de elementos mínimos que potencialmente fazem sentido. Parece ser justamente esse risco que impulsiona o surgimento de novas composições. Ao decifrar ou elaborar charadas, um leitor-tipógrafo é enredado em desvios redundantes, no ir e vir de possibilidades combinatórias, espécie de gaguejo em ziguezague. Talvez, por manter-se muito próximo ao chão da oficina, a experiência do leitortipógrafo coincide com a de um "estreito voo". Porém, é preciso reconhecer que repetidos voos de galinha proporcionavam conhecer e manipular mecanismos técnicos e linguísticos, estabelecendo um ponto de partida, de onde, finalmente, um "leitor-entre-quatro-paredes" poderia lançar-se em voos autorreflexivos mais profundos e auspiciosos.

Todavia, se o leitor-tipógrafo nutriu as bases de uma imaginação tipográfica para Machado, sua pena não seria limitada por fórmulas fáceis. Para caracterizar a violência algo patética da figura de um marido cujo ciúme não o deixa enxergar a esposa amorosa, o autor comparou a desprezível personagem a um leitor de charadas sem imaginação:

Luís Negreiros lançou mão do relógio com uma expressão que eu não me atrevo a descrever. Nem o relógio, nem a corrente eram dele; também não eram de pessoas suas conhecidas. Tratava-se de uma charada. Luís Negreiros gostava de charadas, e passava por ser decifrador intrépido; mas gostava de charadas nas folhinhas ou nos jornais. Charadas palpáveis ou cronométricas, e sobretudo sem conceito, não as apreciava Luís Negreiros. (ASSIS, 2008 [1873], p. 218)

${ }^{2}$ Publicada no Jornal do Comércio, a carta reapareceu em A Marmota na Corte, n. 69, 24 mai. 1850. 


\section{O escritor e o crítico}

Há um encontro simbólico - e solene - que tomamos como ponto de partida para a relação entre Machado de Assis e o crítico José Veríssimo. Morando no Rio havia poucos meses, depois de deixar Belém, no seu estado natal, Veríssimo foi escalado em dezembro de 1891 pelo Jornal do Brasil para representar a publicação na solenidade de colocação da pedra fundamental da estátua de José de Alencar, erguida no bairro carioca do Flamengo, até hoje uma das principais do Rio.

No dia 13 de dezembro de 1891, um domingo, podemos ler a notícia no Jornal do Brasil. Raul Pompeia, apresentado como "o elegante folhetinista do Jornal do Commercio", ficou responsável por ler um auto, assinado pelos presentes, e pôs na abertura da pedra fundamental um baú com moedas brasileiras, obras do autor e os jornais do dia. Participaram representantes de diferentes jornais, parentes de Alencar, sua viúva e filhos, e os escultores Rodolfo e Henrique Bernardelli. Machado ficou responsável pelo momento principal, ao discursar sobre Alencar. Na conclusão desse discurso, reproduzido no Jornal do Brasil, o escritor afirmou: "[...] a posteridade é aquela jandaia que não deixa o coqueiro e que, ao contrário da que emudeceu na novela, repete e repetirá o nome da linda tabajara e do seu imortal cantor. Nem tudo passa sobre a terra" (13 dez. 1891, p. 1).

Naquele segundo semestre de 1891, Veríssimo havia se lançado crítico literário na capital, inventando um espaço para si no Jornal do Brasil, que tinha Joaquim Nabuco como chefe de redação (BERTOL, 2016). Embora fosse republicano, sentia-se à vontade e afinava-se na crítica dos monarquistas, como Nabuco e o dono do jornal, Rodolfo Dantas, à República. Havia ingressado nos círculos de prestígio com $A$ educação nacional, de 1890, lançado em Belém, quando atuou como diretor de instrução pública. Foi com uma série de seis textos em que criticava a política educacional que estreou no Jornal do Brasil, entre julho e agosto. Todavia, nos moldes do crítico romântico Sainte-Beuve e de suas Causeries du Lundi, logo tratou de criar a seção "Às Segundas-feiras", como subtítulo Folhetim Literário, publicada nesse dia no pé da página. Nela, Veríssimo escreveu, em 11 de janeiro de 1892 - um mês depois da solenidade em torno da futura estátua -, a crítica a Quincas Borba, sua primeira a uma obra de Machado no Rio. No texto, rompeu com os critérios "nacionalísticos" de Sílvio Romero e reiterou que sentia cada vez mais vontade de despir-se de fórmulas e escolas. Não se trata de discutir aqui se recaiu então num "impressionismo", como defendem 
Guimarães (2004b) e Barbosa (1974), mas de destacar que, com esse texto, Machado e o crítico selaram uma parceria e uma cumplicidade definitivas.

É um ramo importante do circuito editorial que se reforçava para Machado. Com Veríssimo, ele encontrava um nível de recepção ao qual se afinava. Nas duas décadas seguintes, o crítico se tornaria um dos três maiores de seu tempo e o de mais constante atividade na imprensa. Os outros dois são Sílvio Romero, desafeto de Machado e Veríssimo, e Araripe Júnior. ${ }^{3}$ Souza (2015) afirma que somente no início da República houve no Brasil uma geração de críticos que conseguiu desenvolver uma atividade com certa constância na imprensa a ponto de estabelecer linhas programáticas. Veríssimo é destacado como expoente dessa virada.

Se a crítica de 1892 selou uma parceria, as sociabilidades (circunstâncias além do "papel") não devem ser deixadas de lado para a compreensão do circuito editorial. Assim, antes dessa crítica, o encontro de dezembro de 1891, em torno da futura estátua, pode ser tomado como simbólico para o encontro do escritor com o crítico.

A estátua só seria inaugurada em 1897, no feriado de $1^{\circ}$ de maio, também com uma solenidade expressiva, mas de outro porte. Em vez de singela, foi um acontecimento com a presença de centenas de pessoas sob um intenso calor. ${ }^{4}$ Participaram muitas autoridades, inclusive o presidente da República, Prudente de Morais. Não é possível saber pelos jornais se os escritores estavam presentes. No entanto, podemos associar o episódio a outro acontecimento simbólico de 1897: a criação da ABL, em julho, com um discurso de Nabuco, seu primeiro secretário-geral, para alguns autoproclamados "imortais". Machado, que escolheu Alencar como patrono de sua cadeira, tornou-se, então, o presidente incontestável da agremiação até sua morte, em 1908. Como na expressão que usou para Alencar, foi que ele se tornou o próprio "chefe dos chefes".

Há uma argumentação de Pedro Calmon publicada no Jornal do Brasil, no aniversário de cinquenta anos do periódico, que pode conectar alguns fios dessa história. A folha de Rodolfo Dantas foi criada em abril de 1891 e, em seus primeiros meses, até o fim do ano, contou com Nabuco como principal nome, primeiramente como correspondente em Londres e, no segundo semestre, como chefe de redação. Em novembro, Nabuco e Dantas tiveram de vender suas participações devido à perseguição aos monarquistas.

\footnotetext{
3 Salles destacou no Correio da Manhã (6 jan. 1903) a proeminência dos três, mas lembrou que só Veríssimo era assíduo na imprensa diária. Todavia, ele o acusou de rígido e antipatriota, contrapondoo a Romero e Araripe.

${ }^{4} \mathrm{Na}$ Gazeta de Notícias e no Jornal do Commercio, há o mesmo texto (2 mai. 1897).
} 
Em poucos meses de existência, porém, o Jornal do Brasil conquistou o público. ${ }^{5}$ A verve de Nabuco cumpriu papel importante nisso. A publicação conseguiu indicar "um rumo diferente para a imprensa diária do país" (CALMON, 1941, p. 5), dando-lhe uma força nova e moderada, um sopro conservador e popular diante dos jornais de tintas vermelhas das linhagens jacobinas. "Severo, um tanto frio, correto nos seus moldes ingleses de grande periódico que fala uma língua disciplinada" (CALMON, 1941, p. 5). Em vez de combate, o debate - e nisso se distinguia também de outros periódicos monarquistas, mais inflamados. Tratava-se de voz "ponderada e grave", disse ainda Calmon.

Os redatores do Jornal do Brasil teriam construído uma "política artística, leve e discursiva". Essa política - Calmon concluiu no texto da efeméride - "[...] foi o encanto de um público crescente, o seu manjar diário, sorvido gulosamente há meio século, quando ainda pontificavam no artigo de fundo os homens da abolição e da propaganda" (grifo do autor). Ora, essa seria a mesma política artística posta em prática pela $\mathrm{ABL}$ dirigida por Machado, segundo o artigo de Calmon: "Não há dúvida de que o Jornal do Brasil antecede de seis anos a Academia. Pelo menos, antecipa-lhe o programa" (CALMON, 1941, p. 5). Assim, se 1897 marcou a institucionalização dessa política, "coincidentemente" a memória de Alencar foi simbolicamente institucionalizada na solenidade grandiosa da inauguração da estátua, seis anos depois do lançamento da pedra fundamental.

Nesse sentido, a Revista Brasileira, recriada e dirigida por Veríssimo de 1895 a 1899, foi um elo para esse movimento, que congregou à sua volta praticamente os mesmos personagens de 1891. Nabuco, por exemplo, era presença assídua nos encontros quase diários, realizados no fim da tarde na redação da Revista, onde se planejou a criação da ABL. O regente das articulações foi Machado, que contribuiu para afirmar coletivamente a política artística daquela geração e, ao mesmo tempo, inventou para si um lugar inédito no circuito editorial brasileiro.

A Revista, portanto, foi um projeto coletivo, coordenado e executado por Veríssimo, tendo Machado como fiador de prestígio. O editorial de apresentação da publicação evoca a crítica de Veríssimo a Quincas Borba:

Republicana, mas profundamente liberal, [a Revista Brasileira] aceita e admite todas as controvérsias que não se achem em completo

${ }^{5}$ Sodré (1999) também destaca o sucesso do Jornal do Brasil. 
antagonismo com a inspiração da sua direção. Em Política, em Filosofia, em Arte não pertence a nenhum partido, a nenhum sistema, a nenhuma escola. Pretende simplesmente ser uma tribuna onde todos os que tenham alguma coisa a dizer, e saibam dizê-la, possam livremente manifestar-se. (VERISSIMO, 1895, tomo I, p. 3)

A comprovação (segundo documentos encontrados na pesquisa) ${ }^{6}$ de que a Revista foi mantida, a partir de 1896 (no primeiro ano fora editada pela Laemmert), pela Sociedade J. Veríssimo \& CIA (nome escrito desse modo no documento), para a qual mais de cem pessoas teriam contribuído, embasa o aspecto eclético e coletivo da Revista, que se queria representativa dos intelectuais, em torno da qual superaram divergências, mesmo que provisoriamente. A correspondência de Machado e Veríssimo no período, com inúmeros interlocutores, demonstra o quanto a Revista era um tema central: disputava-se espaço nela. Numa carta a Magalhães de Azeredo, Machado fala da sociedade em comanditas:

Tem lido a Revista Brasileira? Vai passar agora a uma sociedade anônima, com cinquenta contos de capital. Creio que é já no princípio do ano. Tem dado bons trabalhos, e há dedicação da parte dos que escrevem, e muito zelo na direção do José Veríssimo. Amigos deste têm tomado a peito levar a cabo a nova forma da publicação. (ASSIS, carta de 09.12.1895 a Magalhães de Azeredo, 2011, p. 129)

O escritor foi um desses amigos que tomaram "a peito" a iniciativa. Muitos outros aspectos poderiam ser levantados sobre a cumplicidade que unia Machado e Veríssimo na direção da Revista. A própria crítica à vertente "nacionalística" é fator que não pode ser menosprezado numa publicação que tinha a palavra "brasileira" no nome. As seções criadas por Veríssimo e a interlocução com publicações no exterior demonstram seu diálogo não reverente e produtivo com o circuito editorial internacional: com Machado, ele compartilhava o pendor por um "cosmopolitismo literário".

Quando Veríssimo deixou de publicar a Revista Brasileira, em 1899, passou a assinar a coluna "Revista Literária", no Jornal do Commercio, o mais importante da época (sem o tom de crítica acentuada do Jornal do Brasil de 1891). Acompanhamos movimentos editoriais de Machado pelos textos de

\footnotetext{
6 Para mais resultados ver Bertol (2016): a comprovação da sociedade em comanditas é uma informação inédita e muda a perspectiva de estudos sobre a publicação. Os recibos estão na Oliveira Lima Library (EUA). A pesquisa contou com apoio de bolsas da Capes, da Faperj e da Fundação Biblioteca Nacional.
} 
Veríssimo. Na sua estreia no Jornal do Commercio (2 jan. 1899), apontou como um destaque do ano anterior a reedição de Iaiá Garcia. Entre 1899 e 1900, o circuito escritor-crítico se intensifica: Veríssimo escreveu mais três críticas de livros de Machado (e uma, em 1901, sobre Poesias completas, 21 mai. 1901).

Em 10 de julho de 1899, publicou na "Revista Literária" a crítica a Contos fluminenses, outra reedição da Garnier: "[...] são talvez a sua primeira obra de prosador, os seus ensaios num gênero em que havia de ficar em rival entre nós, e não sei se não diga, na língua portuguesa" (VERÍSSIMO, Jornal do Commercio, p. 1). A quase todas essas críticas Machado respondia com agradecimentos em cartas. Veríssimo reparou que a editora havia se "esquecido" de indicar que era uma reedição. Ainda em 1899, veio a lume Páginas recolhidas, com textos da Gazeta de Notícias ("A missa do galo") e da Revista Brasileira, na fase de Veríssimo ("O velho Senado"; a comédia "Tu, só tu, puro amor..."; "Henriqueta Renan"). O volume trouxe o discurso proferido por Machado na solenidade de colocação da pedra fundamental da estátua de Alencar. "Não creio que se tenha melhor caracterizado o gênio e a obra de José de Alencar", comentou Veríssimo na Revista Literária do Jornal do Commercio (18 set 1899, p. 1).

O ponto alto do circuito escritor-crítico foi em 19 de março de 1900, com a crítica a Dom Casmurro na Revista Literária. O texto levantou "uma dúvida sobre a culpabilidade de Capitu, ao considerar suspeito o depoimento de Bentinho. Era o início de uma tese que teria os desdobramentos que todos conhecemos" (ROUANET, 2011, p. xxxi). Naquele dia, Machado escreveu a Azeredo: "Falaram sobre ele [o romance] o Artur Azevedo, ontem, e o José Veríssimo, hoje, ambos com grande simpatia, mas o Veríssimo com mais desenvolvida crítica, segundo costuma" (2011, p. 460).

\section{“Uma estátua por alguns livros!”}

Na crônica de 2 de dezembro de 1894 para "A Semana", o escritor tratou com humor da estátua de Alencar. Naquele domingo, quem por lá passasse em breve veria erguida uma estátua: "Uma estátua por alguns livros!". Para o leitor "examinar se o homem vale o monumento", Machado (diplomático) indicou primeiro um estudo de Araripe Júnior, "imparcial e completo", que acabava de sair em segunda edição: "Ao cabo, fica sempre uma estátua do chefe dos chefes”. A seguir, sugeriu a análise de Veríssimo, que o crítico publicara no Jornal do Brasil sobre Alencar, a propósito justamente da 
solenidade de colocação da pedra fundamental. ${ }^{7} \mathrm{O}$ texto fora reunido no recém-publicado Estudos brasileiros, com esse e outros artigos de Veríssimo do Jornal do Brasil, inclusive a crítica a Quincas Borba. Discreto, Machado afirmou: "Há lá certo número de páginas que mostram que há nele [em Veríssimo] também muita benevolência. Não digo quais sejam: adivinha-se o enigma lendo o livro; se, ainda lendo, não o decifrares, é que não me conheces" (ASSIS, 2008, v. 4, p. 1125).

Machado lança o desafio: era preciso "decifrar" o "enigma". Inclusive, no texto de Veríssimo sobre Alencar citado por ele, há uma crítica negativa ao referido estudo de Araripe Júnior. Veríssimo o considera incompleto... E embora Machado o tenha saudado como "imparcial e completo", sabemos que Araripe era sobrinho de Alencar e dificilmente seria "imparcial".

A crônica reúne dois episódios citados neste artigo, o da estátua e o da crítica a Quincas Borba. Tomamos o encontro em torno da futura estátua como um batismo simbólico, por seu caráter público, do escritor com o crítico, que viriam a estabelecer uma relação perene e multifacetada, com inúmeras portas de entrada para se conhecer o circuito editorial de Machado.

No caso deste artigo, pode ser ainda interessante lembrar que Alencar já brilhava como grande nome, quando Machado era aprendiz de Paula Brito. Da oficina, em seus meandros, ampliamos nosso ponto de vista para um quadro grandioso, de institucionalização diante da nação. Nosso ponto de partida foi a invenção da linguagem na imprensa. Primeiro, o caso da Marmota Fluminense e suas charadas; depois, a invenção de uma política artística no Jornal do Brasil, a qual, por meio da Revista Brasileira, pôde ser consolidada na ABL.

Machado recebe a influência de Alencar na época em que aprende a ser tipógrafo. Como "leitor-tipógrafo", o desconstruiu para talvez chegar a ser "o outro de Alencar", como Monteiro o define: uma "espécie de sparring partner que desempenha o papel incômodo de ser, na nossa imaginação, tudo aquilo que Machado viria a superar" (MONTEIRO, 2014). ${ }^{8}$

A homenagem em torno da estátua, portanto, encerra um jogo sutil no momento em que se almejava a libertação de todas as parcerias, buscando-se ir além da causa "nacionalística" sem preconceitos de escolas ou teorias literárias. "Nessa situação limiar (da literatura e do país), nada mais confortável (e irônico) que saudar o romântico (e monarquista) Alencar

${ }^{7} 14$ dez. 1891, Folhetim Literário - “Às Segundas-feiras”, Jornal do Brasil.

${ }^{8}$ Consulta à edição eletrônica, sem numeração. 
como uma evocativa estátua" (BERTOL, 2016, p. 109). Como diz Machado: "adivinha-se o enigma lendo o livro; se, ainda lendo, não o decifrares, é que não me conheces".

\section{Referências}

ASSIS, Machado de. O relógio de ouro. In: Histórias da meia-noite. [1873]. Obras completas em quatro volumes, 2008.

. Correspondência de Machado de Assis: tomo II, 1870-1889. Coordenação e orientação Sergio Paulo Rouanet. Rio de Janeiro: ABL, 2009.

. Correspondência de Machado de Assis: tomo III, 1890-1900. Coordenação e orientação Sergio Paulo Rouanet. Rio de Janeiro: ABL, 2011.

ALBUQUERQUE, João. O nacional cosmopolitismo de Machado de Assis. In: Machado de Assis em linha, São Paulo, v. 10, n. 21, p. 105-118, agosto 2017.

BARBOSA, João Alexandre. A tradição do impasse: linguagem da crítica \& crítica da linguagem em José Veríssimo. São Paulo: Ática, 1974.

BERTOL, Rachel. A crítica literária em circuitos jornalísticos: José Veríssimo na imprensa da "belle époque" carioca. Tese de doutorado. Programa de PósGraduação em Comunicação e Cultura. Rio de Janeiro: UFRJ, 2016.

CALMON, Pedro. O cinquentenário de um jornal. In: Jornal do Brasil, p. 5, 9 abr. de 1941.

GODOI, Rodrigo Camargo de. Um editor no Império. Francisco de Paula Brito (18091861). São Paulo: Edusp, 2016.

FONSECA, Gondim da. Machado de Assis e o hipopótamo: uma revolução biográfica. São Paulo: Ed. Fulgor Limitada, 1960.

GUIMARÃES, Hélio de Seixas. Os leitores de Machado de Assis: o romance machadiano e o público de literatura no século 19. São Paulo: Nankin Editorial: Edusp, 2004.

. Romero, Araripe, Veríssimo e a recepção crítica do romance machadiano. In: Estudos Avançados. v. 18, n. 51, São Paulo May/Aug 2004b.

MAGALHÃES JÚNIOR, Raimundo. Machado de Assis desconhecido. São Paulo: Civilização Brasileira, 1955.

MARTINS, Bruno Guimarães. Corpo sem cabeça: o tipógrafo-editor e Petalógica. Belo Horizonte: Ed. UFMG, 2018.

MONTEIRO, Pedro Meira. O personagem em ação. Prefácio. In: PASSOS, José Luiz. Romance com pessoas: a imaginação em Machado de Assis. Rio de Janeiro: Objetiva, 2014. (versão eletrônica)

OGIER, R. Manual da tipografia brasiliense. Rio de Janeiro: Typ. e Ed. R. Ogier, 1832. 
ROCHA, João Cezar de Castro. Machado de Assis: por uma poética da emulação. Rio de Janeiro: Civilização Brasileira, 2013.

ROUANET, Sergio Paulo. Apresentação. In: ASSIS, Machado de. Correspondência de Machado de Assis: tomo III, 1890-1900. Rio de Janeiro: ABL, 2011.

SALLES, Antonio. Estudos de literatura brasileira. In: Correio da Manhã, p. 1.6 jan. 1903.

SHAPOCHNIK, Nelson. Malditos tipógrafos. In: RAMOS, A.F., PATRIOTA, R. \& PESAVENTO, S.J. (Orgs.) Imagens na história. São Paulo: Hucitec, 2008.

SODRÉ, Nelson Werneck. História da imprensa no Brasil. $4^{\text {a }}$ ed. Rio de Janeiro: Mauad, 1999.

SOUZA, Roberto Acízelo de. Variações sobre o mesmo tema: ensaios de crítica, história e teoria literárias. Chapecó: Argos, 2015.

RACHEL BERTOL é doutora pelo Programa de Pós-Graduação em Comunicação e Cultura da Universidade Federal do Rio de Janeiro, com sanduíche na Universidade de Princeton, Nova Jersey, Estados Unidos. Docente no Departamento de Comunicação Social da Universidade Federal Fluminense e no Programa de Pós-Graduação em Mídia e Cotidiano (PPGMC) da mesma instituição.

(iD) https://orcid.org/0000-0001-8411-4002 E-mail: rachelbertol@id.uff.br

BRUNO GUIMARÃES MARTINS é doutor em Literatura pelo Programa de Pós-Graduação em Literatura, Cultura e Contemporaneidade da Pontifícia Universidade Católica do Rio de Janeiro. Docente do Programa de Pós-Graduação em Comunicação da Universidade Federal de Minas Gerais e do Deparamento de Comunicação da mesma instituição. É coordenador do Grupo de Pesquisa em Produção Editorial da Sociedade Brasileira de Estudos Interdisciplinares da Comunicação - Intercom (2018-2019). Pesquisador com projetos na Capes e na Fapemig.

(iD https:// orcid.org/0000-0002-1238-3729 E-mail: bruno.morca@gmail.com

Recebido: 15.12.2019

Aprovado: 18.02.2020 